\title{
Confronting the Global Burden of Surgical Disease
}

\author{
Charles Mock
}

Published online: 15 May 2013

(c) Société Internationale de Chirurgie 2013

In the 100 years since the International Society of Surgery was founded, there have been dramatic advances in the field of surgery and anesthesia. Patients with numerous, previously fatal conditions such as severe injuries, malignancies, end-stage kidney or liver failure, and many others can now be successfully treated. Many who had previously led lives of disability and exclusion-persons with club feet, cleft lip, other congenital anomalies, burn wound contractures-are now able to lead normal, active, lives.

Yet the situation is not wonderful. These advances are not available to many people in the world, especially those who live in poverty in low- and middle-income countries. Many pregnant women die from obstructed labor and hemorrhage, without ever having had even basic obstetric care. Many trauma patients die by the roadside or in small peripheral health posts from injuries that could be successfully treated. Many patients with treatable malignancies do not receive any care at all, or only when their disease is unresectable. The same is true for many other surgical conditions.

Part of the solution to this problem involves more of what the surgical community has been good at, including training qualified surgeons and developing new operations. However, much of what is needed to confront the global burden of surgical disease involves activities that we in the surgical field have not traditionally addressed.

- Defining and monitoring the burden of surgical conditions.

C. Mock $(\bowtie)$

Department of Surgery, University of Washington, Seattle, WA 98195, USA

e-mail: cmock@uw.edu
- Defining essential services to which everyone should have access, even in the poorest parts of the poorest countries.

- Promoting and measuring the availability of these essential services, including identifying and confronting barriers to access to care.

- Getting political and promoting access to these essential services as a human right.

These actions have indeed been undertaken for specific subsets of surgical diseases. The best example is the global effort to lower maternal mortality. For the past several decades, many groups have worked to undertake the steps noted above. The burden of maternal deaths has been well defined. In addition to data gathered through vital registry and hospital records, statistical methods have been developed to estimate maternal deaths accurately in the poorest countries, where existing data are unreliable [1-3].

Essential services have been well defined through the dual concepts of having a skilled attendant at every birth and rapid access to emergency obstetric care, especially safe cesarean section [1-3]. These essential services have been promoted through multiple organizations and institutions. The importance of these services has been supported at the highest political levels in the form of Millennium Development Goal 5, working toward an ambitious $75 \%$ reduction in maternal mortality over a 25-year period [4]. Although there is a long way to go, there has nonetheless been significant progress. The overall global number of maternal deaths has gradually come down from around 360,000 in 1990 to 250,000 in 2010 [5].

The trauma care world has been taking similar steps. The number of deaths from injuries globally is fairly reliably known at just over 5 million per year. It has been estimated that around 2 million of these deaths could be 
averted by improvements in trauma care [6]. Essential services have been defined for both prehospital care and hospital-based care collaboratively by the World Health Organization and the International Association for Trauma Surgery and Intensive Care, with input from many other stakeholders [7, 8]. Global political support for improved trauma care has been achieved in the form of World Health Assembly resolution 60.22 (trauma and emergency care services) [9].

Similar steps need to be taken for all surgical conditions. There are, of course, a many capable and dedicated surgeons working in virtually every country in the world, sometimes in difficult circumstances and coming up with innovative solutions. There are also noteworthy efforts to address specific subsets of the surgical picture. However, we are at an early stage of figuring out how to approach surgical care comprehensively and globally.

We need to define the burden of death and disability globally that can be averted by improvements in surgical care. The Disease Control Priorities Project estimated that $11 \%$ of all of the disability adjusted life years (DALYs) lost globally are from conditions that likely require surgery. It was also estimated that the surgically related DALYs were considerably higher in low-income circumstances, ranging from a high of 38 surgical DALYSs/1000 population is Africa to a low of 21/1,000 in the Americas. These estimates were derived primarily by expert opinion [10]. Although these estimates are definitely useful, far more needs to be done to define the overall burden of death and disability avertable by improved surgical care.

We also need to define better the basic essential surgical services that would most effectively lower this burden and that should, and realistically can, be made available to everyone, even in the poorest areas of the world. These services would be those that address the biggest surgically related health problems and that have surgical treatments that are feasible to promote globally [11].

We need to promote these essential surgical services in a comprehensive, concerted fashion globally, with different stakeholders working toward common goals. This includes efforts to promote more widespread availability of the needed human resources (skills, training, staffing), physical resources (equipment, supplies), administrative mechanisms (e.g., quality improvement programs), and financing mechanisms. The latter is especially important as a major hindrance to accessibility of surgical services for a large segment of the world's population is the need to pay in cash, often before care can be provided. The availability of these essential services and the inputs necessary to achieve them must be monitored globally to ensure that they are being achieved. We need to monitor how many people are not getting needed services and the barriers that need to be confronted to achieve universal access.
Finally, political support for access to quality essential surgical services must be garnered. This will not be easy. However, it has been accomplished in a major way for obstetric care (Millennium Development Goal 5) and in at least a preliminary way for trauma care (World Health Assembly resolution 60.22).

The articles in the current issue of World Journal of Surgery represent an important step in achieving the above spectrum of activities. Just to cite a few of the them by way of example: Poenaru et al. [12] define the burden of a subset of surgical disease, surgically correctable disabilities in children. Spiegel et al. [13] discuss the Global Initiative for Emergency and Essential Surgical Care, which has helped define basic essential surgical services for first referral level hospitals. Zafar et al. [14] address disparities in access to surgical care, which is a key component of promoting the availability of essential services. Taken collectively, these articles, and the work of Alliance for Surgery and Anesthesia Presence (ASAP) overall, are an important step in building popular and political support for improved access to surgical services globally. I look forward to continued contributions from ASAP and its members in both the scientific literature and on the advocacy and political front.

\section{References}

1. Rosenfield A (1997) The history of the safe motherhood initiative. Int J Gynaecol Obstet 59:S7-S9

2. Shiffman J (2007) Generating political priority for maternal mortality reduction in 5 developing countries. Am J Public Health 97:796-803

3. Shiffman J, Smith S (2007) Generation of political priority for global health initiatives: a framework and case study of maternal mortality. Lancet 370:1370-1379

4. United Nations (2013) Millenium development goals. http://www.un.org/millenniumgoals/. Accessed 25 Apr 2013

5. Lozano R, Naghavi M, Foreman K (2012) Global and regional mortality from 235 causes of death for 20 age groups in 1990 and 2010: a systematic analysis for the global burden of disease study 2010. Lancet 380:2095-2128

6. Mock C, Joshipura M, Arreola-Risa C et al (2012) An estimate of the number of lives that could be saved through improvements in trauma care globally. World J Surg 36:959-963. doi:10.1007/ s00268-012-1459-6

7. World Health Organization (2004) Guidelines for essential trauma care. WHO, Geneva

8. World Health Organization (2005) Prehospital trauma care systems. WHO World Health Organization, Geneva

9. World Health Organization (2012) WHA Resolution 60.22: health systems: emergency-care systems. http://apps.who.int/gb/ ebwha/pdf_files/WHASSA_WHA60-Rec1/E/reso-60-en.pdf/. Accessed 25 Apr 2013

10. Debas HT, Gosselin R, McCord C et al (2006) Surgery. In: Jamison D, Breman J, Measham A et al (eds) Disease control priorities in developing countries, 2nd edn. Oxford University Press, New York, pp 1245-1260 
11. Mock C, Cherian M, Juillard C (2010) Developing priorities for addressing surgical conditions globally: furthering the link between surgery and public health policy. World J Surg 34: 381-385. doi:10.1007/s00268-009-0263-4

12. Wu VK, Poenaru D (2013) Burden of surgically correctible disabilities among children in the Dadaab refugee camp. World $\mathbf{J}$ Surg. doi:10.1007/s00268-012-1899-Z
13. Spiegel DA, Abdullah F, Price RR et al (2012) World Health Organization global initiative for emergency and essential surgical care: 2011 and beyond. World J Surg. doi:10.1007/ s00268-012-1831-6

14. Zafar SN, Fatmi Z, Iqbal A et al (2013) Disparities in access to surgical care within a lower income country: an alarming inequity. World J Surg. doi:10.1007/s00268-012-1732-8 